DOI: 10.29132/ijpas.376229

İş ve Tarım Makinaları Montajı Yapan Bir Tesiste REFA Standartları ile İş Örneklemesi Uygulaması

\author{
Ömer Nedim Kenger ${ }^{1}$, Zülal Diri Kenger ${ }^{1}$, Zeynel Abidin Çil², Süleyman Mete ${ }^{3 *}$, \\ Hüseyin Karataş ${ }^{1}$, Eren Özceylan ${ }^{4}$ \\ ${ }^{1}$ Gaziantep Üniversitesi, Fen Bilimleri Enstitüsü, Endüstri Mühendisliği Anabilim Dall, Gaziantep, Türkiye \\ omernedim@hotmail.com,zulal-88@hotmail.com, huseyin.karatass@gmail.com \\ ${ }^{2} \dot{I} z m i r$ Demokrasi Üniversitesi, Mühendislik Fakültesi, Endüstri Mühendisliği Bölümü, İzmir, Türkiye \\ cilzeynelabidin@gmail.com \\ 3*Munzur Üniversitesi, Mühendislik Fakültesi, Endüstri Mühendisliği Bölümü, Tunceli, Türkiye \\ suleyman489@gmail.com@ \\ ${ }^{4}$ Gazientep Üniversitesi, Mühendislik Fakültesi, Endüstri Mühendisliği Bölümü, Gaziantep, Türkiye \\ erenozceylan@gmail.com \\ Makale gönderme tarihi: 08.01.2018, Makale kabul tarihi: 02.05.2018
}

$\ddot{O} \mathbf{z}$

Geçmiş yıllarda rekabet ortamı bugünkü kadar zorlu olmadığından şirketler karlarını satış fiyatlarını artırarak sağlayabiliyorlardı. Günümüzde küreselleşen ve büyüyen ortam beraberinde rekabeti getirmiş, bunun neticesinde ise şirketler satış fiyatını artırma şansları olmadığından kar elde edebilmek amacıyla maliyetlerini düşürme yoluna başvurmak zorunda kalmışlardır. Montaj hatlarında maliyeti minimize etmenin en önemli yolu kayıp zamanları tespit ederek, yok etmek veya minimum seviyeye indirmektir. Kayı zamanların tespitinde uygulanabilecek en ucuz, emeği en düşük ve en kısa sürede sonuca ulaşılabilecek yöntem ise iş örneklemesidir. Bu çalışmada iş ve tarım makinaları montajı yapan bir işletmede REFA (Reichsausschuss Für Arbeitszeitermittlung) standartları ile iş örneklemesi uygulaması yapılmıştır. Örneklemeler istatistiksel metotlar ile belirlenmiş ve kayıp zamanlar için çözüm önerileri getirilmiştir.

Anahtar Kelimeler: İşörneklemesi, montaj hattı, REFA

\title{
Work Sampling Using REFA: A Case Study in a Construction and Agricultural Vehicles Company
}

\begin{abstract}
In recent years, the competition environment was not as challenging as it is today, so companies could increase profits by increasing their selling prices. However, the companies have to reduce costs in order to be able to make profit in these days due to fact that the globalization has brought competition environment. The one of the most important way to minimize cost in assembly lines is to eliminate or minimize non-productive times. Work sampling is one of the cheapest and the simple method in order to determine the non-productive times. In this study, work sampling is applied with the REFA (Reichsausschuss Für Arbeitszeitermittlung) standards in a company that assemble construction and agricultural vehicles. The samples are determined by statistical methods and certain recommendations are offered to eliminate non-productive times.
\end{abstract}

Keywords: Work sampling, assembly line, REFA

\section{GíRiş}

Montaj hatları, bir taşıyıcı sistem ile birbirine bağlanan iş istasyonlarında bir ürünün seri bir şekilde montajının gerçekleştiği ve her işçinin belirli bir görev kümesi üzerinde çalıştığı yerlerdir (Diri ve ark., 2015; Mete ve Ağpak, 2013). Günümüz rekabet koşullarında İş ve Tarım Makinaları sektöründe maliyetlerin ve teslimat sürelerinin en aza indirgenmesi gerekliliği önem kazanmıştır ve İş ve Tarım Makinaları montaj hatlarında hem maliyet hem de teslimat sürelerini azaltmanın yolu kayıp zamanları azaltarak, verimliliği artırmaktan geçmektedir. Kayıp zamanları azaltmak için öncelikle kayıp zamanların tespit edilmesi gerekmektedir. Kayıp zamanların tespit edilmesi için de iş ölçümü teknikleri uygulanmaktadır.

İnsan faktörleri ve örgüt araştırmacılarının ilgilendiği temel konu, insanların mesai saatlerini nasıl harcadığı, özellikle de yaptıkları işler ve 


\section{DOI: 10.29132/ijpas.376229}

çalışma saatinin işler arasında nasıl dağıldığıdır (Robinson, 2010). Bu dağılımları tespit etmek için iş ölçümü tekniklerinden yararlanılmaktadır. Birkaç iş ölçümü tekniğinden biri olan İş Örneklemesi diğer yöntemlere göre emeği düşük ve kısa sürede çözüme ulaşması sebebi ile öncelikli ve etkin bir yöntem olarak tercih edilmektedir. İş örneklemesi yönteminde belirli zaman aralıklarında veriler toplanır ve bir etkinlikle ilgili gözlemlerin yüzdesine dayalı olarak etkinlikte harcanan toplam çalışma süresinin parçaları hakkında çıkarım yapılır (Finkler ve ark., 1993).

İş örneklemesi konusundaki ilk çalışma 1935 y1lında tekstil sanayi alanında L.H.C. Tippet tarafından geliştirilmiştir (Güner ve ark., 2007). O zamandan itibaren iş örneklemesi tekniği kayıp zamanları azaltarak verimliliği artırmak ve maliyetleri en aza indirmek amaciyla birçok sektörde uygulanmıştır. $\mathrm{Bu}$ uygulamalardan bazıları çalışma kapsamında incelenip listelenmiştir. Kiremitçi ve Meriç (2001), hazır giyim alanında üretim yapan iki farklı işletmede iş örneklemesi çalışması yapmışlar ve sonuçları analiz etmişlerdir. Karyağdı (2001), iş örneklemesi yöntemini vergi dairesi çalışanlarının analizini yapmak için kullanmıştır. Güner ve ark. (2007), bir hazır giyim işletmesinde çalışanların kayıp zamanlarını belirleyebilmek için iş örneklemesi metodu kullanmıştır. Güneşoğlu ve Meriç (2007), giyim endüstrisinde çalışanların görevlerini ve bu görevlerin dağılım oranlarını araştırmış; boş zamanları ve kişisel nedenlerle verilen araları analiz etmişlerdir. Ünal (2013), iş örneklemesi metodu kullanarak bir hazır giyim atölyesindeki ceket ütüleme bandında çalışan işçiler için REFA standartlarını kullanarak performans değerlendirmesi yapmış ve verimsiz işlerin nedenlerini saptamıştır. Güner ve ark. (2017), Ege Üniversitesi Tekstil Mühendisliği Bölümü’ndeki öğrencilerin ders içerisinde göstermiş oldukları faaliyetleri ve ders dişı faaliyetleri belirleyerek dersi daha verimli bir hale getirmek amacıyla iş örneklemesi yöntemine başvurmuşlardır. Martinec ve ark. (2017), otomotiv sanayinde çalışan personel faaliyetlerinin iş örneklemesi yöntemiyle belirlenmesi ve bu faaliyetlerin kullanılan bilgi işleminin biçimini ve niteliğini nasıl etkilediğini ortaya koyan bir çalışma yapmışlardır.
$\mathrm{Bu}$ çalışmada ise REFA standartları kullanılarak İş ve Tarım Makinaları montajı yapan bir işletmede kayıp zamanların belirlenmesi ve verimliliği artırmak amacıyla iş örneklemesi yöntemi uygulanmıştır. Yapılan literatür araştırmasına bağlı olarak (yazarların bildiği kadarıyla) montaj hatlarında iş örneklemesi yöntemi ilk defa bu çalışmada uygulanmıştır.

Çalışmanın bir sonraki bölümünde uygulama alanından bahsedilmiştir. Daha sonra kullanılan yöntem ayrıntılı bir şekilde açıklanmıştır. Bir sonraki bölümde çalışmanın sonuçları verilmiş ve hemen ardından tespit edilen sorunlar için çözüm önerileri getirilmiştir. Son olarak genel bir sonuç bölümü ile çalışma özetlenmiştir.

\section{MATERYAL}

$\mathrm{Bu}$ çalışma iş ve tarım makinaları üretimi yapan, modern teknoloji ile donatılmış bir tesiste gerçekleştirilmiştir. Ulusal sanayimize önemli katkı sağlayan bu tesisin montaj hattında 6 adet iş istasyonu ve 28 adet çalışan bulunmaktadır.

İş ve tarım makinaları tesisindeki kayıp zamanları en aza indirgemek için 6 adet iş istasyonlarında gözlemler alınarak iş örneklemesi yapılmıştır. Akış türlerinin planlı ve plan dışı olmak üzere iki ana başlık altında detaylarına inilmiştir.

\section{YÖNTEM}

İş örneklemesi sekiz adım dikkate alınarak uygulanmaktadır (Karyağdı, 2001).

\section{Amaç Belirleme}

Çalışmanın amacı iş ve tarım makinaları montaj hattında bulunan altı iş istasyonundaki planlı ve plan dışı faaliyetleri detaylarına inerek saptamak olarak belirlenmiştir.

\section{Akış Türleri Belirlenmesi ve Tanımı}

Belirlenen altı iş istasyonunda kısa gözlemlerle ayırt edilebilir akış türleri tanımlanmıştır. Tanımlanan akış türleri Çizelge 1 'de gösterilmiştir. 
DOI: 10.29132/ijpas.376229

Çizelge 1. İş akış türleri

\begin{tabular}{|c|c|c|}
\hline Nr. & Akış Türleri Tanımı & $\begin{array}{l}\text { Faaliyet } \\
\text { Türü }\end{array}$ \\
\hline 1 & Ana Faaliyet & \multirow{18}{*}{$\begin{array}{c}\text { Planlı } \\
\text { Faaliyet }\end{array}$} \\
\hline 2 & Yan Faaliyet & \\
\hline 2.1 & $\begin{array}{l}\text { Montaja yardımcı hazırlık } \\
\text { faaliyetleri }\end{array}$ & \\
\hline 2.2 & Malzeme ve ekipman taşıma & \\
\hline 2.3 & Paket açma & \\
\hline 2.4 & Planlı Yürüme & \\
\hline 2.5 & Diğer & \\
\hline 3 & Akış Gereği Ara Verme & \\
\hline 3.1 & 2.Eleman çalışırken bekleme & \\
\hline 3.2 & $\begin{array}{l}\text { Vardiya başı ve vardiya sonu } \\
\text { temizlik }\end{array}$ & \\
\hline 4 & Ek Faaliyet & \\
\hline 4.1 & $\begin{array}{l}\text { Malzeme, ekipman arama ve temin } \\
\text { etme }\end{array}$ & \\
\hline 4.2 & Kalite hatalarl giderme & \\
\hline 4.3 & Arıza ve aksamaya müdahale etme & \\
\hline 4.4 & Malzeme teslim alma faaliyeti & \\
\hline 4.5 & ALPATA işlemleri & \\
\hline 4.6 & Hat dişı işlemler & \\
\hline 4.7 & Dĭger & \\
\hline 5 & Aksama Nedeni ile Ara Verme & \multirow{11}{*}{$\begin{array}{l}\text { Plansız } \\
\text { Faaliyet }\end{array}$} \\
\hline 6 & Kişisel Nedenlerle Ara Verme & \\
\hline 6.1 & Wc gitme, su ve sigara içme & \\
\hline 6.2 & Namaz & \\
\hline 7 & Ara Verme Zamanları & \\
\hline 7.1 & İşe geç gelme,erken bırakma & \\
\hline 7.2 & Özel konuşma ve keyfi çalışmama & \\
\hline 8 & $\begin{array}{l}\text { Uzun Süreli ( } 30 \text { Dak. fazla) } \\
\text { Durus }\end{array}$ & \\
\hline 8.1 & Diğer birimlerde çallşma & \\
\hline 8.2 & Izin ve Rapor & \\
\hline 8.3 & Diğer & \\
\hline
\end{tabular}

\section{Tur Planının Belirlenmesi}

Planlanan gözlemler için işletme içerindeki istasyonların krokisi üzerinden tur planı saptanmıştır.

\section{Gözlem Sayısının Belirlenmesi}

Birçok akademik çalışmada olduğu gibi iş örneklemesinde de temel olarak istatiksel yöntemler esas alınır. Belirlenen bir güvenirlik düzeyi ve doğruluk derecesi ile "N" adet gerekli gözlem sayısı aşağıdaki formül ile belirlenmiştir.

$$
N=\frac{z^{2} p(1-p)}{h^{2}}
$$

$N$ : İstenen gözlem sayısı (örnek büyüklüğü)

$z$ : İstenen güvenirlik düzeyindeki standart sapma say1s1

$p$ : Örneklem içinde oluş oranı

$q$ : Örneklem içinde olmama oranı $h$ : Mutlak hata miktarı (Örneklem büyüklüğünün doğruluk sınırları, duyarlık)

\section{Tur Zamanlarının Belirlenmesi}

Öncelikli olarak 5460 gözlem sayının 20 güne yayılmasına karar verilmiştir. Daha sonra gözlem yapılacak saat ve dakikalar için rassal sayılar tablosu kullanılarak tur zamanları rassal olarak belirlenmiştir.

\section{Etüdün Uygulanması}

Gözlemler tur saatlerine uyarak yapılmıştır ve kayıt altına alınmıştır.

\section{Ara Değerlendirme}

Yapılan ara gözlemde istenilen güvenirlik seviyesine ulaşı1dığı için ek gözlem yapılmamıştır.

\section{Son Değerlendirme}

Son değerlendirmede her faaliyet için toplam gözlem içerisindeki yüzdelik değerler hesaplanmıştır. İş örneklemesi sonucunda elde edilen verilerin kullanılabilirliğine karar verilmiştir. Gözlemlenen faaliyetler ile ilgili bilgiler Çizelge 2'de verilmiştir.

\section{BULGULAR}

Montaj hattındaki altı istasyonda yapılan 5460 gözlem sonucu, kayıp zaman oranı $\mathrm{P}=$ \%33.05 olarak belirlenmiştir. $\mathrm{Bu}$ çalışmanın istatistiksel güvenilirlik testi yapıldı̆̆ında; \%95 olas1l1kla, kayıp zaman oran1 \%33.05 in (+/-) \%1.25 güven aralığ içerisinde değişebileceği güvence altına alınmıştır. Yani \%95 olasılıkla, plan dışı (kayıp) zaman oranının, \%31.80 ile \%34.30 aralığında kaldığı istatistiksel olarak gösterilmiştir.

Tüm iş istasyonları için genel değerlendirme formları incelendiğinde çalışanların mesai sürelerinin \%66.95'nin planlı zaman ile geçtiği, \%33.05'inin ise plan dışı (kayıp) zaman kullanımı içinde oldukları sonucu ile karşılaşılmıştır. Plan dışı (kayıp) zaman kullanım oranlarını oluşturan ek faaliyet, aksama nedeni ile ara verme, kişisel nedenlerle ara verme ve keyfi ara verme zamanları toplamı \%33.05 olarak belirlenmiştir. $\mathrm{Bu}$ oranı kendi içerisinde organizasyonel kayıplar ve kişisel kayıplar olarak ikiye ayırarak incelemekte fayda vardır. Öncelikle organizasyonel kayıplarda en dikkat 


\section{DOI: 10.29132/ijpas.376229}

çekici olan, ek faaliyet altında yer alan \%6.23'lük kayıpla malzeme ekipman arama ve temin etme görülmektedir. İkinci dikkat çeken kayıp ise yaklaşı $\% 3$ civarı ile kalite hataları gidermedir. Arıza ve aksamaya müdahale etmek için çalışanlar mesai sürelerinin yaklaşık \%3'ünü kullanmaktadır.

Kişisel nedenlerle ara verme zamanlarını da kişisel ihtiyaçlar ve keyfi ara verme zamanları şeklinde ayırmakta yarar vardır. Kişisel ihtiyaçlar için kullanılan zamanlar, çalışanların gün içerisinde (WC, Sigara İçme vb.) ihtiyaçlarını karşılamak amacıyla kullandıkları zamanlardır. Uluslararası standartlarda bu oran mesai süresinin \%4'ü kadardır. Türkiye' de ortalama \%6 civarında yaşanmaktadır. İşletmede ise \%6.41 civarındadır. Görülüyor ki Türkiye ortalamasının biraz üzerindedir. Keyfi ara verme zamanları (işe geç gelme, erken birakma, özel sohbetler, cep telefonu ile görüşmeler ve keyfi olarak işi kesintiye uğratmalar) montaj çalışanlarının mesai süresinin \%10.48'ini almaktadır.

Çizelge 2. Gözlemlenen faaliyetler

\begin{tabular}{|c|c|c|c|c|c|c|c|c|c|c|c|c|c|c|c|}
\hline \multicolumn{2}{|r|}{ 1. ÍSTASYON Tur saatleri } & \multicolumn{2}{|c|}{ 1. İST. } & \multicolumn{2}{|c|}{ 2. İST. } & \multicolumn{2}{|c|}{ 3. İST. } & \multicolumn{2}{|c|}{ 4. İST. } & \multicolumn{2}{|c|}{ 5. İST. } & \multicolumn{2}{|c|}{ 6. İST. } & \multicolumn{2}{|r|}{ TOP. } \\
\hline $\begin{array}{ll}\mathrm{Nr} \\
.\end{array}$ & Akış Türleri Tanımı & $\mathbf{x}$ & $\%$ & $\mathbf{x}$ & $\%$ & $\mathbf{x}$ & $\%$ & $\mathbf{x}$ & $\%$ & $\mathbf{x}$ & $\%$ & $\mathbf{x}$ & $\%$ & $\mathbf{X t}$ & $\%$ \\
\hline & & & 24.3 & 20 & 35.3 & 28 & 46.6 & & 39.0 & & 42.7 & & 41.5 & 165 & 37.2 \\
\hline 1 & Ana Faaliyet & 238 & 1 & 2 & 1 & 0 & 7 & 473 & 6 & 386 & 0 & 74 & 7 & 3 & 0 \\
\hline & & & 34.9 & 19 & 33.2 & 11 & 18.5 & & 25.6 & & 21.5 & & 27.5 & 119 & 26.9 \\
\hline 2 & Yan Faaliyet & 342 & 3 & 0 & 2 & 1 & 0 & 311 & 8 & 195 & 7 & 49 & 3 & 8 & 6 \\
\hline & & & 16.9 & 11 & 19.4 & & 10.6 & & & & & & & & 12.1 \\
\hline 2.1 & Montaja yardımcı hazırlık faaliyetleri & 166 & 6 & 1 & 1 & 64 & 7 & 94 & 7.76 & 86 & 9.51 & 17 & 9.55 & 538 & 1 \\
\hline & & & 11.0 & & & & & & 13.0 & & & & & & 10.1 \\
\hline 2.2 & Malzeme ve ekipman taşıma & 108 & 3 & 41 & 7.17 & 40 & 6.67 & 158 & 5 & 87 & 9.62 & 15 & 8.43 & 449 & 0 \\
\hline 2.3 & Paket açma & 20 & 2.04 & 9 & 1.57 & 5 & 0.83 & 48 & 3.96 & 9 & 1.00 & 3 & 1.69 & 94 & 2.12 \\
\hline 2.4 & Planlı Yürüme & 45 & 4.60 & 28 & 4.90 & 2 & 0.33 & 9 & 0.74 & 13 & 1.44 & 13 & 7.30 & 110 & 2.48 \\
\hline 2.5 & Diğer & 3 & 0.31 & 1 & 0.17 & 0 & 0.00 & 2 & 0.17 & 0 & 0.00 & 1 & 0.56 & 7 & 0.16 \\
\hline 3 & $\begin{array}{l}\text { Akış Gereği Ara Verme } \\
\text { 2.Eleman. makine çallşırken akış gereği }\end{array}$ & 25 & 2.55 & 13 & 2.27 & 22 & 3.67 & 44 & 3.63 & 15 & 1.66 & 5 & 2.81 & 124 & 2.79 \\
\hline 3.1 & bekleme & 6 & 0.61 & 2 & 0.35 & 1 & 0.17 & 16 & 1.32 & 1 & 0.11 & 1 & 0.56 & 27 & 0.61 \\
\hline 3.2 & Vardiya başı ve vardiya sonu temizlik & 19 & 1.94 & 11 & 1.92 & 21 & 3.50 & 28 & 2.31 & 14 & 1.55 & 4 & 2.25 & 97 & 2.18 \\
\hline & & & 14.4 & & 13.4 & & 15.1 & & 20.1 & & 12.7 & & 14.0 & & 15.5 \\
\hline 4 & Ek Faaliyet & 141 & 0 & 77 & 6 & 91 & 7 & 244 & 5 & 115 & 2 & 25 & $\begin{array}{r}4 \\
11.2\end{array}$ & 693 & 9 \\
\hline 4.1 & Malzeme. ekipman arama ve temin etme & 60 & 6.13 & 18 & 3.15 & 42 & 7.00 & 67 & 5.53 & 70 & 7.74 & 20 & 4 & 277 & 6.23 \\
\hline 4.2 & Kalite hatalart giderme & 14 & 1.43 & 16 & 2.80 & 2 & 0.33 & 75 & 6.19 & 24 & 2.65 & 1 & 0.56 & 132 & 2.97 \\
\hline 4.3 & Arıza ve aksamaya müdehale etme & 19 & 1.94 & 26 & 4.55 & 20 & 3.33 & 40 & 3.30 & 14 & 1.55 & 3 & 1.69 & 122 & 2.75 \\
\hline 4.4 & Malzeme teslim alma faaliyeti & 1 & 0.10 & 0 & 0.00 & 6 & 1.00 & 14 & 1.16 & 1 & 0.11 & 0 & 0.00 & 22 & 0.50 \\
\hline 4.5 & ALPATA işlemleri & 2 & 0.20 & 0 & 0.00 & 5 & 0.83 & 8 & 0.66 & 0 & 0.00 & 0 & 0.00 & 15 & 0.34 \\
\hline 4.6 & Hat dışı işlemler (eksik tamamlama) & 9 & 0.92 & 4 & 0.70 & 7 & 1.17 & 15 & 1.24 & 5 & 0.55 & 1 & 0.56 & 41 & 0.92 \\
\hline 4.7 & Diğer & 36 & 3.68 & 13 & 2.27 & 9 & 1.50 & 25 & 2.06 & 1 & 0.11 & 0 & 0.00 & 84 & 1.89 \\
\hline 5 & Aksama Nedeni ile Ara Verme & 4 & 0.41 & 0 & 0.00 & 4 & 0.67 & 15 & 1.24 & 1 & 0.11 & 1 & 0.56 & 25 & 0.56 \\
\hline 6 & Kişisel Nedenlerle Ara Verme & 60 & 6.13 & 27 & 4.72 & 29 & 4.83 & 55 & 4.54 & 73 & 8.08 & 10 & 5.62 & 254 & 5.72 \\
\hline 6.1 & Wc gitme.su ve sigara içme & 60 & 6.13 & 27 & 4.72 & 29 & 4.83 & 55 & 4.54 & 73 & 8.08 & 10 & 5.62 & 254 & 5.72 \\
\hline 6.2 & Namaz & 8 & $\begin{array}{l}0.82 \\
17.2\end{array}$ & 3 & $\begin{array}{l}0.52 \\
11.0\end{array}$ & 4 & $\begin{array}{l}0.67 \\
10.5\end{array}$ & 10 & 0.83 & 6 & $\begin{array}{l}0.66 \\
13.1\end{array}$ & 0 & 0.00 & 31 & $\begin{array}{l}0.70 \\
11.1\end{array}$ \\
\hline 7 & Ara Verme Zamanları & 169 & 6 & 63 & 1 & 63 & 0 & 69 & 5.70 & 119 & 6 & 14 & 7.87 & 497 & 8 \\
\hline 7.1 & İşe geç gelme.erken birakma & 6 & $\begin{array}{l}0.61 \\
15.8\end{array}$ & 1 & $\begin{array}{l}0.17 \\
10.3\end{array}$ & 11 & 1.83 & 5 & 0.41 & 43 & 4.76 & 4 & 2.25 & 70 & 1.58 \\
\hline 7.2 & Özel konuşma ve keyfi çalışmama & 155 & 3 & 59 & 1 & 48 & 8.00 & 54 & 4.46 & 70 & 7.74 & 10 & 5.62 & 396 & 8.91 \\
\hline & & & 22.5 & 22 & 39.8 & 20 & 33.3 & & 15.6 & & 19.4 & & & 101 & 22.8 \\
\hline 8 & Uzun Süreli ( 30 Dak. fazla) Duruş & 221 & 7 & 8 & 6 & 0 & 3 & 189 & 1 & 176 & 7 & 2 & 1.12 & 6 & 6 \\
\hline & & & 13.1 & 10 & 18.3 & 12 & 20.1 & & 12.7 & & 13.0 & & & & 14.1 \\
\hline 8.1 & Diğer birimlerde çalı̧̧ma & 129 & 8 & 5 & 6 & 1 & 7 & 154 & 2 & 118 & 5 & 1 & 0.56 & 628 & 3 \\
\hline & & & & 12 & 21.5 & & 13.1 & & & & & & & & \\
\hline 8.2 & $\dot{I}$ zin ve Rapor & 92 & 9.40 & 3 & 0 & 79 & 7 & 35 & 2.89 & 56 & 6.19 & 0 & 0.00 & 385 & 8.66 \\
\hline 8.3 & Diğer & 0 & 0.00 & 0 & 0.00 & 0 & 0.00 & 0 & 0.00 & 2 & 0.22 & 1 & 0.56 & 3 & 0.07 \\
\hline & & 120 & & 80 & & 80 & & 140 & & 108 & & 18 & & 546 & \\
\hline & Toplam & 0 & 100 & 0 & 100 & 0 & 100 & 0 & 100 & 0 & 100 & 0 & 100 & 0 & 100 \\
\hline
\end{tabular}




\section{DOI: 10.29132/ijpas.376229}

Günümüz işletmelerinde bu kayıp kabul edilebilir bir kayıp değildir. Nedenleri araştırılarak önlem alınmalıdır. Planlı kullanılan zamanlar incelendiğinde kendi içerisinde Ana Faaliyet, Yan Faaliyet ve İş Akışı Gereği Ara Verme şeklinde sınıflandırıldığı gözlenmiştir ve planlı zamanlar için geçen süre oranı mesai süresinin $\% 66.95{ }^{\prime} \mathrm{i}$ olarak saptanmıștır. Bu \%66.95 zaman kullanım oranının ise esas katma değer yaratan kısmı ana faaliyet oranı olup bunun değeri sadece \%37.19'dur. Görülüyor ki çalışanların planlı olarak kullandıkları zamanın \%26.97'si katma değer yaratmayan yardımc1 faaliyetler için harcanmaktadır. Bunların bir kısmının doğrudan montaj faaliyetlerine etki etmediği gözlemlenmiştir. Örneğin; Malzeme ve Ekipman Taşıma, Paket Açma, Planlı Yürüme gibi faaliyetler üzerinde durulması gereken önemli iyileştirme alanlarıdır. Yan faaliyet oranları azaldığı ölçüde katma değer yaratan ana faaliyet oranları yükselecektir.

Saptanan kayıp zamanlarla ilgili kök nedenler ve çözüm önerileri sonraki bölümde belirtilmiştir.

\section{KÖK NEDENLER VE ÇÖZÜM ÖNERILERI Tedarik A ̆ğ Geliştirilmesi}

Malzeme, ekipman arama ve temin etme ile ilgili \%6.23'lük kayıp araştııılmış ve kök nedenler olarak malzeme tedarikinin zamanında sağlanmaması ve depo yönetimindeki eksiklikler tespit edilmiştir. Çözüm olarak; satış planları revizyonlarının malzeme tedarik süreleri dikkate alınarak yapılmas1, stok takip sisteminin iyileştirilmesi, tedarikçi yönetim sisteminin geliştirilmesi, alternatif tedarikçi listeleri oluşturulması, depo çalışan sayısının ve yetkinliklerinin gözden geçirilmesi önerilmiştir.

\section{Kalite Kontrol}

Dikkat çeken kayıplardan biri olan \%3'lük kalite hataları ile ilgili kök nedenler ise üretim kaynaklı kalite problemleri, tedarikçi hatalı parçalar sebepli kalite problemleri ve projenin tedarikçiye yanlış iletilmesi sonucu oluşan kalite problemleri olarak tespit edilmiştir. Çözüm olarak; tedarikçi kaynaklı hatalarda istasyonda düzeltmek yerine tedarikçiye iade yapılması, tedarikçideki proje resimlerinin sürekli güncel tutulması, ürün ambar kabul esnasındaki kalite kontrol noktalarının artırılması, montaj yapan elemanın işin gerektiği kalifiyede olması ve iş başı eğitimlerin artırılması önerilmiştir.

\section{Düzen}

Yapılan analizlerde dikkat çeken bir başka nokta yan faaliyetlerin \%26.96'l1k yüksek bir orana sahip olmasıdır. Kök nedenler araştırıldığında, 5S eksikliği, alan yetersizliği, yanlış yerleşim planı, taşıma araçlarının yetersizliği, malzemelerin ambalajının depo yerine montaj esnasında açılması, malzeme erişim zorlukları olduğu belirlenmiştir. Çözüm olarak, 5S'in aktif olarak uygulanması, yerleşim planının gözden geçirilmesi, alan yetersizliği probleminin çözülmesi, taşıma araçlarının iyileştirilmesi, ambalajların depoda açılması önerilmiştir.

\section{Kişisel Nedenler}

Gözlemlenen bir başka kayıp faaliyet ise kişisel nedenler ile ara vermenin \%5.72'lik yüksek bir orana sahip olması olmuştur. Kök nedenleri araştırıldığında, çalışanların doğru hedeflerle yönetilmediği, ödül sisteminin olmadığı, hatta dengeleme problemleri sebebi ile çalışanların boşta kalması, motivasyon problemleri saptanmıştır. Çözüm olarak, tempo değerlendirmeli zaman ölçümleri yapılarak iyi bir bant dengeleme çalışmasının uygulamaya girmesi, montaj bantlarının hedefleri yakalama ve aşma durumlarında çalışanlara heyecan duyacakları bir ödül sisteminin devreye sokulması, çalışan memnuniyeti analizleri yapılarak çalışanların daha yüksek motivasyon ile çalışacakları sistemlerin geliştirilmesi, anket uygulamasından çıkan sonuçların çalışanlarla paylaşılması önerilmiştir.

Planlı ve plansız faaliyetlerin ölçümler sonucu elde edilen oranları şekil 1'de gösterilmiştir. Planlı ve plansız faaliyetlerin alınan ölçümlere göre dağılımı şekil 2'de gösterilmiştir. 


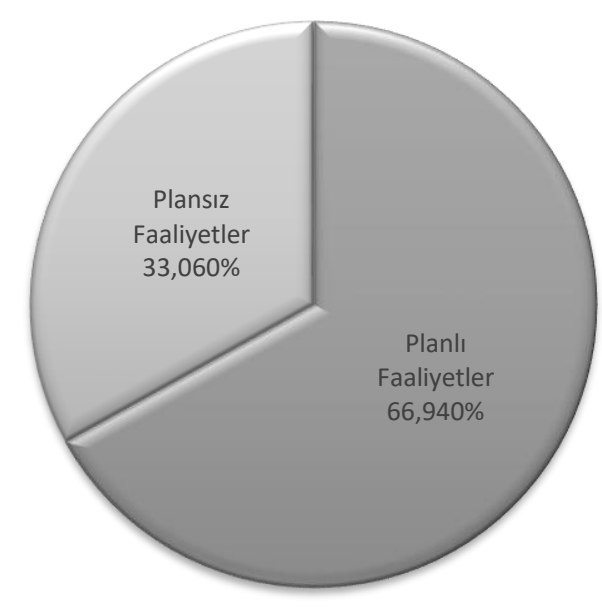

Şekil 1. Planlı ve plansız faaliyetler

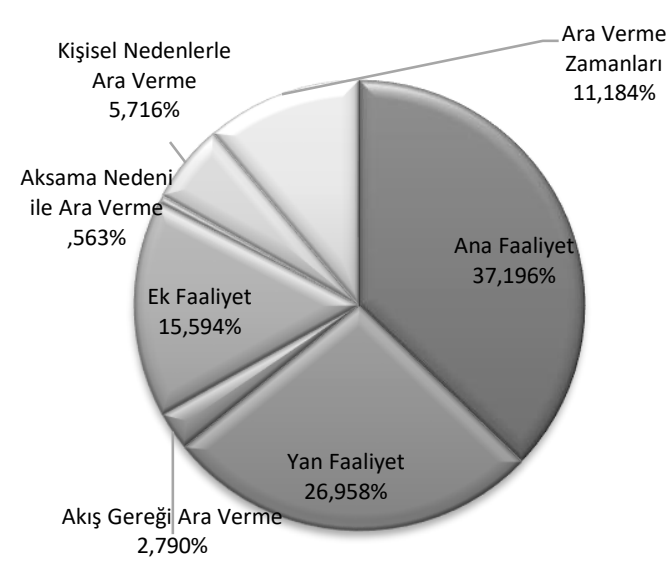

Şekil 2. Faaliyetler dağglımı

\section{SONUÇLAR}

İşletmeler ekonomilerde sınırların ortadan kalkmasiyla beraber hem ulusal hem de uluslararası alanda rekabet içine girmek zorunda kalmışlardır. $\mathrm{Bu}$ rekabet ortamı içerisinde işletmeler devamlılık sağlamak için rekabet stratejilerini etkin bir şekilde kullanmak zorundadır. İş örneklemesi yöntemi ile işletmedeki verimsiz faaliyetlerin tespiti ve bu faaliyetlerin en aza indirilmesi hem üretimdeki verimlilikte artış sağlamakta hem de zorlu rekabet ortamında işletmeleri bir adım daha öne geçirmektedir. Bu sebeple bu çalışmada İş ve Tarım Makinaları montajı yapan bir işletmede kayıp zamanların tespiti ve verimliliği artırmak amacıyla REFA standartları kullanılarak iş örneklemesi yöntemi uygulanmıştır. Çalışma montaj hatlarında REFA standartlarını kullanarak iş örneklemesi yöntemi uygulayan ilk çalışmadır. İş ve Tarım Makinaları montaj1 yapan bu işletmede pilot bölge olarak seçilen montaj hattında iş süreçlerinin kayıp ve israflarını belirlemek amacı ile 6 iş istasyonunda ayrı ayrı iş örneklemesi yöntemi uygulanmış, bu görev yerlerinde faaliyet gösteren 28 çalışan üzerinde 20 gün süre ile toplam 5460 anlık gözlem alınmıştır. Tüm iş istasyonları için genel bir değerlendirme yapıldığında çalışanların mesai sürelerinin \%66.95'nin planlı zaman ile geçtiği, $\% 33.05$ te ise plan dışı (kayıp) zaman kullanımı içinde oldukları sonucu ile karşılaşılmıştır. Gelişmiş ülkelerdeki işletmeler ile karşılaştırıldığında kayıp zaman oranının oldukça fazla olduğu tespit edilmiş ve çalışma kapsamında kayıp zamanların en aza indirilmesi için bazı çözüm önerileri sunulmuştur.

\section{KAYNAKLAR}

Diri, Z., Mete,, S., Çil, Z.A., Ağpak, K., 2015. Stokastik Sıra-Bağımlı Hazırlık Zamanlı Montaj Hatt1 Dengeleme Problemi. Pamukkale Üniversitesi Mühendislik Bilimleri Dergisi, 21(4), 152-157.

Finkler, S.A., Knickman, J.R., Hendrickson, G., Lipkin, M., Thompson, W.G., 1993. A Comparison of Work-Sampling and Time-andMotion Techniques for Studies in Health Services Research. Health Services Research 28:5.

Güner, M., Küçük, M., Acar, E., 2017. Üniversite Öğrencilerinin Ders Esnasındaki Davranışlarının İş Örneklemesi Yöntemiyle Değerlendirilmesi. Düzce Üniversitesi Bilim ve Teknoloji Dergisi, 5:15-22.

Güner, M., Yaşatan, İ., İlleez, A.A., 2007. Bir Konfeksiyon İşletmesinde Ofis Çalışanlarının Kayıp Zamanlarının İş Örneklemesi Yöntemiyle Belirlenmesi. Tekstil ve Mühendis Dergisi, 14(68), 28-38.

Güneşoğlu, S., Meriç, B., 2007. The Analysis of Personal and Delay Allowances Using Work Sampling Technique in Sewing Room of a Clothing Manufacturer. International Journal of Clothing Science and Technology, 19, Nr:2, pp: 145 .

Karyağdı, N., 2001. Toplam Kalite Yönetimi ve Türk Vergi İdaresi. Ankara Sanayi Odası Yayını, No: 51.

Kiremitci, S., Meriç, B., 2001. Konfeksiyon İşletmelerinde Dağılım Zamanları Üzerine Bir Araştırma. Tekstil ve Konfeksiyon, 1:44-56.

Martinec, T., Skec, S., Savsek, T., Perisic, M.M., Work sampling for the production development: A case study of a supplier in European automotive industry. Advances in Production Engineering and Management, 12(4): 375-387. 
DOI: 10.29132/ijpas.376229

Mete, S., Ağpak, K., 2013. Çok Amaçlı Genelleştirilmiş Kaynak Kısıtlı Çift Taraflı Montaj Hattı Dengeleme Problemi ve Hesaplama Analizi. Gazi Üniversitesi Mühendislik Mimarlık Fakültesi Dergisi, 28(3):567-576.

Robinson, M.A., 2010. Work Sampling: Methodological Advances and New Applications. Human Factors and Ergonomics in Manufacturing and Service Industries, 20 (1) 42-60.

Ünal, C., 2013. Takım Elbise Üretiminde Ütü Departmanı Süreçlerinin ve Çalışan Performansının Değerlendirilmesi. Tekstil ve Mühendis, 20(89): 28-35. 